\title{
DIRECT SALES OF AGRICULTURAL COMMODITIES
}

\author{
Mrs.A.Anitha ${ }^{[1]}$, Mrs.P.Kanaga Lakshmi ${ }^{[2]}$, Dr. M. Vargheese $^{[3]}$, S.Nandhini ${ }^{[4]}$, P. Karunya Devi ${ }^{[5]}$, \\ N. Shanmugapriya ${ }^{[6]}, M_{\text {. Subbulakshmi }}{ }^{[7]}$ \\ ${ }_{1,2,3}$ Assistant Professor, ${ }^{4,5,6,7}$ UG Students \\ Department of Computer Science and Engineering, PSN College of Engineering and Technology, \\ Melathediyoor, Tirunelveli.
}

\begin{abstract}
The most fundamental people who offer nourishment for sale to the public and accordingly connect with clients are ranchers and retailers. Numerous food varieties and high-quality materials are made by ladies in the provincial district under the MAHILA UDYOG, which offers an assortment of things. Ladies in provincial regions who are essential for MAHILA UDYOG may make an assortment of things and acquire a benefit from them. These days, ranchers are stood up to with an assortment of issues, remembering an absence of return for their produce, like vegetables and organic products. The rancher sold their merchandise at a modest expense, however, its fairly estimated worth is very high because numerous wholesalers and sellers hold stock, and the market worth of the item ascends because of item deficiencies. Accordingly, we made an Android App connect the distance between the provincial and metropolitan regions, just as to resolve the issues related to tackling this issue. Ranchers can't offer them to the individual they pick since they don't go to the market or vendors don't contact any of the ranchers since their contacts are restricted. Subsequently, we'll make an application that takes care of the issue of ranchers and merchants selling wares with accommodation and reliability. The rancher's responsibility is to transfer the products, while the merchant's responsibility is to put orders using the online installment framework. The retailer may see the dirt's evaluating, which is given by the Indian government. On the off chance that the rancher's Soil Health Card shows that the dirt quality is amazing, the shipper may essentially verify that the item is similarly fantastic. Subsequently, he can buy the merchandise from that rancher. The Soil Health Card is validated utilizing an OCR innovation when the rancher transfers it to the framework
\end{abstract}

Keywords- Android app, Mahila Udyog, Farmer, Retailer, Soil Health card, OCR.

\section{INTRODUCTION}

Keen Live Stock Trading is an idea where rancher can sell their item in a savvy route for the retailer and acquire a great benefit on each selling. This framework helps Farmer and retailers to straightforwardly speak with one another and they can do a superior business among them. A huge number of smallholders in the agricultural nation are dealing with this significant issue of resource cultivating to higher pay. Numerous reasons impact the ranchers to make direct market linkage with merchants in different urban communities. Indeed, even you find in a country region numerous ladies make their board of trustees and produce a few items which are utilized by everybody in everyday life yet at the same time they don't have any stage to upgrade their thought and develop their business. Ranchers and traders are the key people that take care of food kinds and then connect with clients. Ranchers cannot provide them to the person they desire, as they do not go to the lookout or as their connections reach the base the dealer did not contact any of the ranchers.
So, in exchange for the commodity, we shall plan the application, which will take care of the problem of both the farmer and the trader. The rancher's job is to transfer the items and the merchant's job is to arrange them utilizing the web installment as the installment choice. Every item added ought to be given the directions of their reality, and the merchant can choose whether he needs a conveyor he will pick the merchandise without anyone else. Along these lines, to settle this hole between the provincial region and metropolitan region and difficulties to take care of this issue, As an Android app, we suggested a new framework. For the two ranchers just like retainers, this program is straightforward to use and credible.

\section{LITERATURE SURVEY}

The essay "Ladies Empowering to Develop India" proposed by A.Priyadharshini, R.Thiyagaraian, V.Kumar, T.Radhu This article discusses issues of women's everyday life looking, plans for future enhancements accessible to women in India, and a self-help group that operates effectively in the Tamil Nadu area, self-help groups(SHG), and the contextual research of women's empowerment cells. This article discusses This issue. This document presents women from rural areas with many strategies who may do business and establish up their self-help group which is just as beneficial as their public. Ladies Empowerment will make India an all-around created country. Not just ladies in towns should be engaged, yet ladies in urban communities additionally should be prepared in actual security [1], based on this exploration we choose to give a stage in the type of Android application where ladies in the country region can sell their item straightforwardly to buyer and acquire great benefit.

Abishek A.G, Bharathwaj M., BhagyalakshmiL. developed an "Agribusiness marketing using web-based and mobile technology" framework in which ranchers and shoppers contact one other directly for their systemic sales and purchased products without the support of a centerman or any expert. This proposal eliminates the middle man between rancher and buyer, but it did not provide women a stage to promote their goods[2], One thing additionally we can see is that the hole among rancher and customer is filled by this framework however installments are finished by the shopper to a rancher or the other way around are manual which isn't gone under Online exchange act. These days Indian Government is advancing on the web exchange which is secure and simple. Thus, to beat these issues we offer a stage to ladies to sell their result of our application just as an online exchange framework also.

Soumya Gupta, Gaurav Trivedi proposed the framework that presents and give point by point data on an Android-based multilingual application, "e-krishakMitra" which focuses to give 
arrangement/idea to the ranchers dependent on their area and the current weather condition in regards to the development of appropriate yields according to the application from Indian Metrological Department utilizing rancher's area and is contrasted and the climate conditions needed by the harvests reasonable to fill in the specific soil[3], this application coordinates the different parts of ranchers however doesn't give them office to sell their items.

Soumalya Ghosh, A.B. Garg, Sayan Sarcar, P.S.V.S Sridhar, Ijasvi Maleyvar, Raveesh Kapoor, proposed an article "KrishiBharati: An Interface for Indian rancher", in this article writer proposed a framework which interfaces the Indian rancher local area to get to the horticulture data from the worldwide web archive and store them into neighborhood vault. In this framework rancher can communicate with the web and get data identified with seeds, organic products, vegetables and so on Rancher can likewise change the language as indicated by their accommodation [4], however, they can't sell their item just they will get data identified with their items.

Manav Singhal, Kshitij Verma, Anupam Shukla proposed an android application, "Krishi Ville-Android based Solution for Indian Agriculture", it is an android based versatile application which would deal with with with updates, rural items, climate gauge refreshes, horticultural news refreshes. We can say that this application useful for rancher which assist them with thinking about the all the data identified with their homestead, market esteem and can contact to Krishi Vigyan Kendra[5], however, this application can't fill the hole between the rancher and purchaser which is serious issue looked by a rancher.

Bo ZHAO, Jianxin, LIU, proposed an article "Exploration on the model development of current green horticulture items inventory network", this examination paper or an article dissected the conventional agribusiness items production network, model. This framework expresses that green agrarian item supply to green rural creation coordinations focus and then to store from that point customer will go to take the item. All these interactions are tracked by utilizing GPS from creation focus to customer. This framework will supportive for ranchers and it will diminish the danger of decay of food varieties grains, vegetables, and so on [6] however again here we can see that ranchers can't straightforwardly contact the customer, and it is for some time prepared.

Sindhu M R, Aditya Pabshettiwar, Ketan.K.Ghumatkar, Pravin.H. Budhehalkar, Paresh.V.Jaju, proposed "E-FARMING" as their undertaking which is a site which gives different offices to a rancher to sell their result of numerous highlights and rancher can straightforwardly connect with the retailer, get each information identified with cultivating and whether gauging [7], however, there are no highlights in that sites to pay GST to Government of India during an installment of the item, No validation, rating, and audit of the item quality. These sites don't give any office to the MAHILA UDYOG panel; these boards of trustees are an additional significant piece of the rustic region we can't overlook. As a result of every one of these issues, the current framework isn't doable for the rancher to give the legitimate office to retailer too as a retailer can't impart as expected.
Ghodke Tushar D, Devde Nitin N, Agwan Sagar C, Kudal Yogesh N, proposed an application as "E-FARMING: an Innovative Approach for an Indian Farmer" this application or site will assist rancher with getting notice of different plan through Government, regardless of whether estimating data, crops rates for everywhere on India and they will get credit office. These frameworks assist them with taking care of different issues [8], yet identified with cultivating here still rancher doesn't immediately associate with dealers. This paper expresses that rancher will get all data just as credits from the bank yet it was not giving any stage to the rancher and MAHILA UDYOG to deal their item and procure great benefit.

Santosh G.Karkhile1, Sudarshan G.Ghuge2, proposed an Android application named "A Modern Farming Techniques utilizing Android Application" this framework is an android application which assists rancher with getting data about the weather forecast, they will handily get instrument as per their need [9], yet rancher won't connect with retailer and won't deal there item. Indeed, even this application can't cooperate with the retailer or the instrument's supplier straightforwardly. Again this application won't be accommodating for the rancher to showcase their item straightforwardly to the client and procure great benefit.

D.K.Joshi, Samir B. Dambhe, Amit V.Kotecha, Pushkar N.Jaju, proposed "KrishiConnect" which is a web administration application with which ranchers and retailers can associate one another and ranchers can deal their item. This web administration fills the hole among rancher and retailer and straightforwardly connect however everything done by rancher and retailer during the trade of homestead item and installment is manual [10]. The online exchange office is absent. Indeed, even this web administration doesn't confirm soil, since, in such a case that we would the farmer be able to give the evidence of his/her ranch soil that it's been well decent then we can say that if soil quality is acceptable than item additionally will be acceptable.

N. Venkata Rao, A.S.C.S.Sastry, A.S.N.Chakravarthy, Kalyanchakravarthi P, proposed an article "Optical Character Recognition Technique Algorithm" it presents a new neural organization based strategy for optical character acknowledgment just as written by hand character acknowledgment. This paper gives numerous thoughts and different procedures like Matrix Matching, Fuzzy Logic, highlights Extraction, Structural Analysis, and a lot more to perceive the optical character from picture [11]. We will utilize Google Cloud Vision API to get Optical Character Recognition, we will utilize this element to extricate the worth of soil quality and give the proportion of the dirt 


\section{PROPOSED SYSTEM}

In the wake of contemplating the current framework we had tracked down that different issue like the hole among rancher and customer, online exchange, there is no stage or any framework where ladies can work and acquire the benefit so to beat these issues we proposed our new framework, which gives an office to SHG, a rancher can straightforwardly contact to the shopper, warning caution, Helpline number, transport arrangement, online exchange, and so forth In our undertaking, there are five significant modules:

1. Mahila Udyog.

2. Farmer.

3. Retailer.

4. Payment mode.

5. Review and Rating.

\section{A. MAHILA UDYOG:}

Mahila Udyog is the panel of women who meet in these councils and develop the array of items that are beneficial in our daily lives. Below figure 1: Mahila Udyog's employment has shown. It is a meeting of 10-20 women who collaborate with various initiatives presented to their community by the governmental authorities. [1] This framework can support you directly and may provide wonderful benefits for your customers by selling such Papad, Pickle, bamboo, mat, pot, etc. [4].

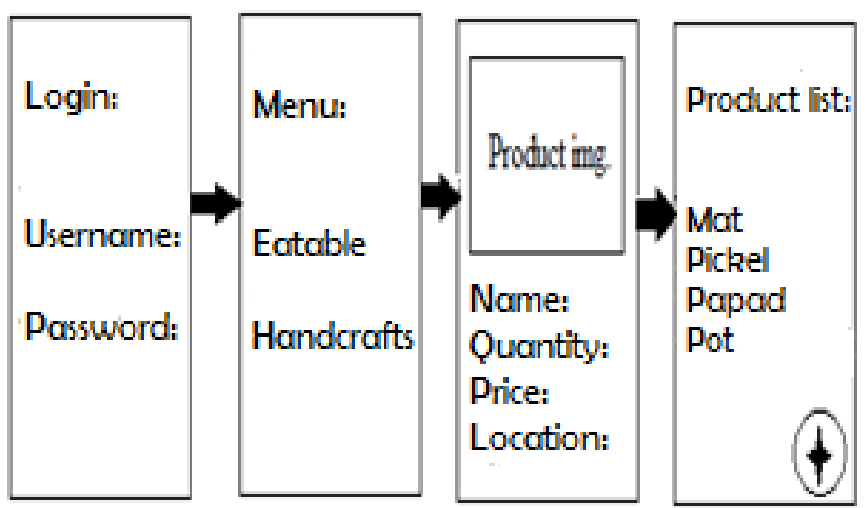

Fig. 1. Role of Mahila Udyog.
This application or a framework will assist ladies with straightforwardly collaborating with a market situated far away from their region and assist them with offering their item to the buyer and think about different offices. You will include your record in the app and utilize it to sell the thing that helps you to achieve the fantastic advantages and show off your goods. The shop may arrange item requests and pay the amount online. The trustees' board will present each data recognized beside an area from which a store might purchase his item. After each request for the retailer, they get the notice regardless of whether an application isn't dynamic or the client gadget isn't associated with the web.

This framework will help the women in rural regions working under MAHILA UDYOG, who have the best opportunity to sell their items in a provincial area and have a source to bring in income.

\section{B. FARMER:}

In figure 2 below: a rancher's responsibility is to enter this program and log in. To add the item and data that is connected with the item, Rancher will hit Add Catch. You may move the object from anywhere and you may select the region by using the Google Map to set your shop or part of your business.

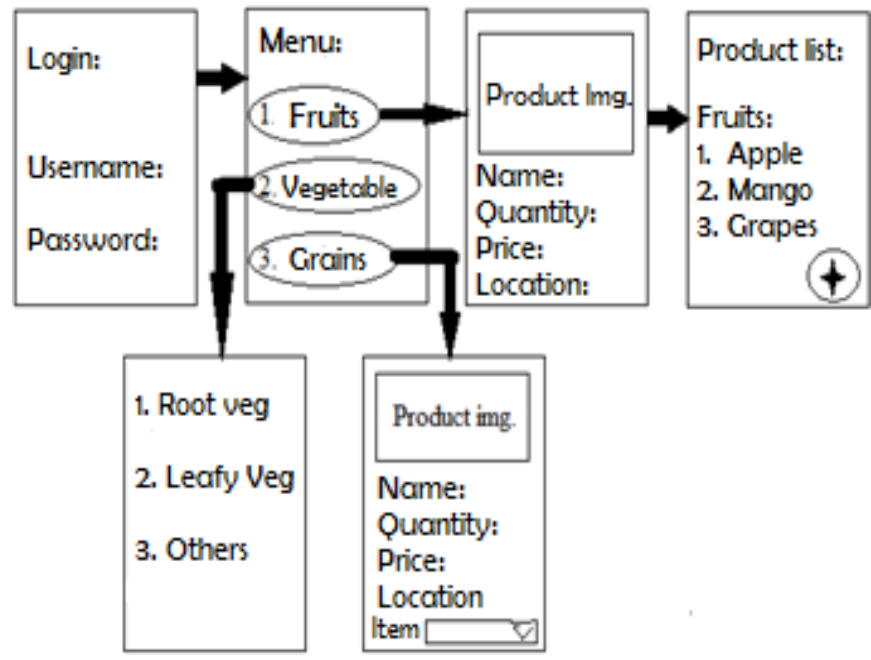

Fig. 2. Role of farmer

The rancher may view the requests list in which he can view the number of requests he has received today, from where he got them, and who is making the request. Rancher will also upload a Soil Health Card certificate to the item on the photo simultaneously, the testament using the OCR approach being checked before it is sent by ranchers. When any retailer applies, the rancher will get an announcement where all the data for name, contact, product are stored, and so at one point rancher may log into the application list merely to check the application list after logging into a frame. 
Suppose a farmer wants any type of assistance relating to agriculture and can call him to offer the hotline number.

\section{RETAILER}

Figure 3: the retailer's task is that after a successful login, the retailer can see the item he wants to buy and he can even look at the item through the alternative channel.

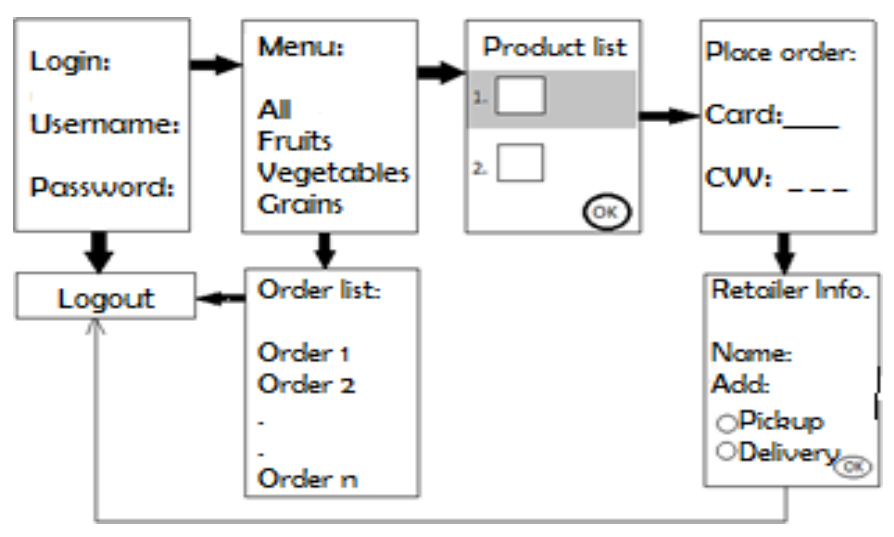

Fig. 3. Role of retailer

He may also use the channel selection to sort the rundown by name, sort by zone. Suppose it picks the plants alternative, therefore it is also possible to pick leafy vegetables, root vegetables, cereals, or plants. The retailer can buy an item from several farmers and load it on the truck at the same time. Sometime later, he may complete and request all the installment data that select the installation mode. A store can also view what he has requested in the application.

\section{PAYMENT MODE:}

At the point when retailer going to choose the numerous items from the diverse rancher, it will go to include the truck where retailer at long last picked the item as indicated by its need and purchase the item. In the wake of tapping on the purchase button, Payment mode is opened to complete the details of the card by the retailer.

\section{Backend of Payment Mode}

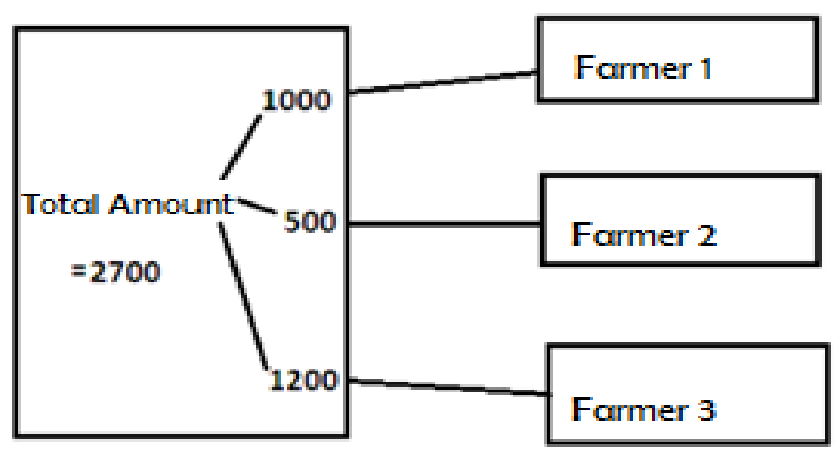

Fig. 4. Payment mode
The store will fill up the data indicated by the exchange, such as the card number, the address sum, etc. GST will be the material for the purchase of the article after the installation is completed in Figure 4: explain how retailer amounts are dispersed in their item price among the specific rancher. The back end of the installation mode structure is each of these capabilities. This total transfer may be discovered without any problems in the information base. A rancher can view all measurements of this list of requests.

\section{E. REVIEW AND RATING:}

The authentication modules play a major part. Clicking on the option of uploading certificates as indicated in Figure 5 when farmers load certificates: And the camera opens to snap photographs automatically. After the picture has been acquired, it is transformed into an editable OCR technology format.

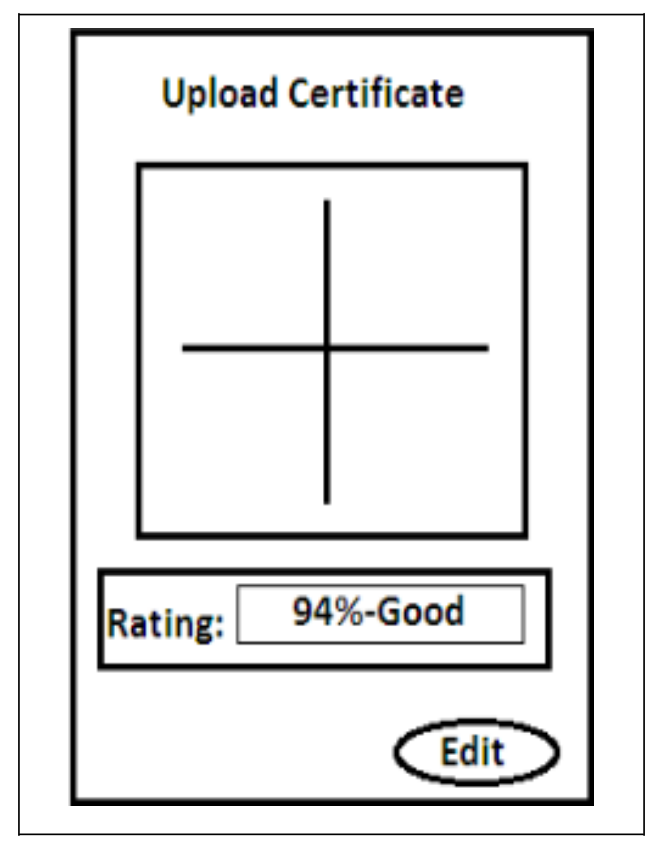

Fig. 5. Certificate uploaded by the farmer.

The soil health card provided by the Government of India to determine the components and that portion will be included in the evaluation section will be selected by Rancher. If the dirt rating is acceptable that the item is also acceptable, the shop may determine that the product quality is acceptable or not. Soil grades are presented right below the endorsement and if a picture statement becomes murky when the image is taken in that direction, the rancher has an option that may easily adjust his authentication. The retailer may also do a star audit once the rancher has transmitted the goods well and the retailer may select its number one rancher by simply clicking on the heart symbol. This decision makes it easy to browse through their rancher number one. 


\section{RESULT AND DISCUSSION}

Application Programming Interface:

\section{A. Google Cloud Vision API:}

Google Cloud Vision API enables programmers with an easyto-use REST API to understand the contents of an image. It quickly picks images from hundreds of categories, detects individual articles and faces inside images, and detects and reads printed text inside images. You can manufacture metadata, regulate hostile substances or enable new advertising conditions for slanting screening on your image list. Search for images sent on the Google Cloud Storage request or coordinate with your image stock. [12] [13]. We extract the contents from the SOIL HEALTH CARD using this API and give the rating as per the nature of the dirt.

\section{B. Restful API:}

This file contains the relative variety of features used to talk with the data set as capabilities. Each of the capabilities is not used simply on the principle thread yet on the asynchronous task and we parse the JSON object in the string format using other class JSONParse. A RESTful API is an application interface that uses GET, PUT, POST, and DELETE information for HTTP requests. A RESTful API — sometimes referred to as a RESTful internet administration - is a technique to deal with the typically used interchanges of online management and authentic state move innovations. [14]. This API will use to associate the information base with our application.

\section{Graphical User Interface}

The clients can connect to an app or device using the GUI or the Graphical User Interface. Illustrations of any framework should be straightforward to use so that the customer can interact without problems with the frame. It is quite straightforward to use and may be used as a store for both ranches. If a customer must first review this application, the customer must input its login and secret key. Click on Registration and fill up the required information for registration. In Figure 6, the customer will pick the location where he/she needs to be enlisted if the customer taps on the "Select Enrolment type" format. They would pick the sort of customer as per their calls. The following page that will be the enlistment page will be the client type determination.

\section{CONCLUSION}

This work will help farmers interact with the store, and a direct sales approach may make excellent use of the rancher. This application closes the gap between retailers and farmers just as the Self Help Group (SHG) can sell its products and make significant profits. Before giving ranchers that kind of office like ladies in provincial regions, there are no such requests. They are therefore in constant contact with new cultivation tactics and trends. However, the new customer may experience some concern about its use to some degree. This framework is generally faster, safer, and pleasant. That was our responsibility in system designing Android as a Web application based on Java language for "Rancher Trader Application." We are doing a great deal to develop this framework. We believe that this framework has given us all a great deal of fulfillment. Even if each company is never meant to be ideal for this sector of progress, much more may be expected in this application to enhance. Generally, for iOS and in the different adjacent languages we may implement this framework.

\section{REFERENCES}

[1] A.Priyadharshini, R.Thiyagarajan, V.Kumar, T.Radhu "Ladies Empowerment towards Developing India", Region 10 Humanitarian Technology Conference (R10-HC), IEEE, 2016.

[2] Abishek A.G, Bharathwaj M., Bhagyalakshmi L., "Rural Marketing Using Web and Mobile Based innovation", Technological Innovations in ICT for agriculture and Rural Development (TIAR), IEEE, 2016.

[3] Soumya Gupta, Gaurav Trivedi, "ekrishakMitra", International Conference on Accessibility to Digital World (ICADW), IEEE, 2016.

[4] Soumalya Ghosh, A.B. Garg, Sayan Sarcar, P.S.V.S Sridhar, Ijasvi Maleyvar, Raveesh Kapoor, "Krishi-Bharati: An Interface for Indian Farmer", Students' Technology Symposium, IEEE, 2014.

[5] Manav Singhal, Kshitij Verma, Anupam Shukla, "Krishi Ville-Android based Solution for Indian Agriculture", Fifth IEEE International Conference on Advanced Telecommunication Systems and Networks (ANTS), IEEE, 2011.

[6] Bo ZHAO, Jianxin, LIU, "Exploration on the model development of current green farming items production network", International Symposium on IT in Medicine and training, IEEE, 2011.

[7] Sindhu M R, Aditya Pabshettiwar, Ketan.K.Ghumatkar, Pravin.H. Budhehalkar, Paresh.V.Jaju, "E-Farming", Sindhu M R et al,/International Journal of Computer Science and Information Technologies, Vol. 3 (2),3479-3482, IJCSIT, 2012.

[8] Ghodke Tushar D, Devde Nitin N, Agwan Sagar C, Kudal Yogesh N, "E-Farming: an Innovative methodology for an Indian Farmer", International Journal on Recent and Innovation Trends in Computing and Communication, Volume: 3 Issue: 9, IJRITCC, 2015

[9] Santosh G.Karkhile1, Sudarshan G.Ghuge2, "A Modern Farming Techniques utilizing Android Application", International Journal of Innovative Research in Science, Engineering and Technology, Vol. 4, Issue 10, IJIRSET, 2015.

[10] D.K.Joshi, Samir B. Dambhe, Amit V.Kotecha, Pushkar N.Jaju, "KrishiConnect", IRACST - International Journal of Computer Science and Information Technology and Security (IJCSITS), ISSN: 2249-9555, Vol. 3, No.1, IJCSITS, 2013. 